\title{
Pulmonary perfusion quantified by electron-beam computed tomography: effects of hypoxia and inhaled NO
}

\author{
A.T. Jones*, D.M. Hansell ${ }^{\#}$, T.W. Evans*
}

\begin{abstract}
Pulmonary perfusion quantified by electron-beam computed tomography: effects of hypoxia and inhaled NO. A.T. Jones, D. M. Hansell, T.W. Evans. C ERS Journals Ltd 2003.

ABSTRACT: Patients with acute lung injury may benefit from the manipulation of pulmonary blood flow using inhaled nitric oxide (iNO) to optimise ventilation/perfusion matching. Current techniques for studying changes in regional pulmonary perfusion are difficult to apply clinically. This study therefore investigated the potential of electronbeam computed tomography (EBCT) to quantify the effects of hypoxia and iNO on regional pulmonary perfusion in five healthy subjects.

Contrast-enhanced sections were obtained sequentially under conditions of normoxia, hypoxia (fractional concentration of oxygen in inspired gas $\left(F, O_{2}\right) 0.12$ ) and hypoxia, with iNO (14.8 parts per million (ppm)) administered during inspiration in the supine position. Regions of interest were placed along the nondependent to dependent axis and values for relative perfusion derived.

Under normoxic conditions a vertical gradient of perfusion existed, which became less apparent due to increased perfusion in nondependent regions after the induction of hypoxia $\left(F I, O_{2} 0.12\right)$. The addition of iNO $\left(F I, O_{2} 0.12\right.$ and NO $\left.14.8 \mathrm{ppm}\right)$ increased perfusion in all regions of the lung section, suggesting redistribution of pulmonary perfusion from other regions of the lung. Absolute values of perfusion were comparable to those documented with existing techniques.
\end{abstract}

The use of a high spatial-resolution technique confirmed the presence of marked perfusion heterogeneity between anatomically close regions of lung.

Eur Respir J 2003; 21: 855-861.
*Unit of Critical Care and ${ }^{\#}$ Dept of Imaging National Heart and Lung Institute, Imperial College of Science, Technology and Medicine, Royal Brompton Hospital, London, UK.

Correspondence: T.W. Evans

Royal Brompton Hospital

Sydney St

London

SW3 6NP

Fax: 44171358524

E-mail: t.evans@rbh.nthames.nhs.uk

Keywords: Computed tomography

hypoxia

pulmonary perfusion

Received: September 132002

Accepted after revision: January 102003

A.T. Jones was supported by a Smith and Nephew Fellowship Work supported in part by the British Lung Foundation.
Under physiological circumstances, the distribution of pulmonary blood flow is regulated by a local action of alveolar oxygen tension on precapillary pulmonary vessels. Thus, the reflex of hypoxic pulmonary vasoconstriction (HPV) ensures that blood flow is diverted away from areas of damaged lung, thereby preserving the matching of ventilation $\left(V^{\prime}\right)$ and perfusion $\left(Q^{\prime}\right)[1,2]$. In contrast, patients with acute lung injury (ALI) demonstrate diminished HPV leading to adverse changes in $V^{\prime} / Q^{\prime}$ matching, manifesting clinically as refractory hypoxaemia [3]. The favourable manipulation of $V^{\prime} / Q^{\prime}$ therefore assumes considerable therapeutic significance. In this context, nitric oxide (NO), an endothelially derived vasodilator that modulates vascular tone in health and disease [4], has been demonstrated to be a selective pulmonary vasodilator when administered by inhalation both in experimental animals [5, 6] and humans [7], improving physiological variables (specifically pulmonary artery pressure $(P$ pa $)$ and arterial oxygen tension) in patients with ALI [4]. The effects of NO on HPV in terms of the modulation of changes in regional pulmonary blood flow induced by hypoxaemia are, however, unknown.

Although techniques for studying regional pulmonary perfusion have been difficult to apply clinically, a gravitational distribution of pulmonary perfusion has been described in normal subjects, determined by the interrelationship between hydrostatic, alveolar and interstitial pressures [8, 9]. Moreover, animal studies employing high spatial-resolution techniques suggest that the influence of gravity is less important than the structure of the pulmonary vascular tree in determining regional blood flow in the lung $[10,11]$. The authors have recently employed electron-beam computed tomography (EBCT) to quantify regional pulmonary perfusion in normal subjects placed in the supine and prone positions, demonstrating that a gravitational gradient of pulmonary perfusion existed in both supine and prone positions [12].

The aims of the current study, in normal subjects using EBCT, were therefore three-fold. First, changes in the regional distribution of pulmonary perfusion induced by hypoxaemia were explored. Secondly, the effects of inhaled NO (iNO) on modulating regional pulmonary blood flow under hypoxic conditions were evaluated. Thirdly, the effects of spatial resolution on the apparent distribution of pulmonary perfusion in adult human subjects were further investigated.

\section{Methods}

The experimental protocol, to which all subjects provided written, informed consent, was approved by the Ethics Committee of the Royal Brompton Hospital and was designed to minimise radiation exposure. The effective dose for each subject was $3.3 \mathrm{mSv}, \sim 33 \%$ of the effective radiation dose of a conventional contiguous computer tomography (CT) of the thorax, or equivalent to 1.5 yrs of background radiation. In all studies, subjects were placed in the supine position within the CT scanner (Imatron C150L; Imatron Inc., San Francisco, CA, USA). Following a separate period of training, all subjects were established on intermittent positive pressure ventilation (IPPV) administered via a mouthpiece (Evita II; Drager, Lubeck, Germany), using a tidal volume $(V T)$ of 
8-10 $\mathrm{mL} \cdot \mathrm{kg}^{-1}$. IPPV was used throughout the study in order to first provide a closed system whereby inspired oxygen concentration and iNO concentration could be effectively controlled and any adverse atmospheric pollution avoided. Secondly, CT scans were performed during an inspiratory breath-hold manoeuvre (ventilator mediated) in an effort to standardise scanning conditions. Thirdly, the authors wished to standardise the experimental conditions to those used successfully in earlier studies using this technique [12].

\section{Computed tomography scanning protocol}

For the purpose of constructing time/density curves, a rapid multisection scan acquisition was performed at a single level, immediately prior to and following a rapid, automated injection (60 mL at $20 \mathrm{~mL} \cdot \mathrm{s}^{-1}$, Angiomat 6000; Liebel-Flarsheim Company, Cincinnati, OH, USA) of radio-opaque contrast material (Omnipaque $300 \mathrm{mg}$ Iodine (I) $\mathrm{mL}^{-1}$; Nycomed, Amersham, $\mathrm{UK})$, via a $16 \mathrm{G}$ cannula placed in an antecubital fossa vein. In each study, 15-20 sections $(6 \mathrm{~mm})$ were obtained. The acquisition time for each section was $100 \mathrm{~ms}$. The interval between the acquisition of each image was designed to allow construction of complete time/density curves for the lung parenchyma and left-sided circulation (descending aorta). The scans were electrocardiogram (ECG)-gated and each series was performed at full inspiration using the ventilator breathholding control. Following completion of the experimental protocol (see below) a calibration study was performed using a bandoleer of extruded acrylic tubes, each containing an incremental concentration $\left(0-18 \mathrm{mg} \cdot \mathrm{mL}^{-1}\right)$ of iodinated contrast. The bandoleer was placed upon foam sections so that it was in the centre of the scanner's reconstruction circle.

\section{Administration of hypoxic gas mixture and inhaled nitric oxide}

Previous work has shown that a fractional concentration of oxygen in inspired gas $\left(F I, \mathrm{O}_{2}\right)$ of $0.12-0.14$ results in reproducible hypoxic pulmonary vasoconstriction $[13,14]$. To permit the administration of both an $F \mathrm{I}, \mathrm{O}_{2}$ of 0.21 and 0.12 in the ventilator circuit, the ventilator air intake was connected in the usual fashion to the wall supply, and the oxygen $\left(\mathrm{O}_{2}\right)$ intake to a cylinder of $12 \% \mathrm{O}_{2}$ in nitrogen $\left(\mathrm{N}_{2}\right)$ (BOC Special Gases, Sunningdale, UK). To achieve normoxia, the $\mathrm{FI}, \mathrm{O}_{2}$ control dial of the ventilator was set at 0.21 . Under such conditions all gas is taken from the wall supply. To achieve hypoxic conditions $\left(F \mathrm{I}, \mathrm{O}_{2} 0.12\right)$ the dial was set at 1.0 , under which conditions all gas was taken from the $\mathrm{O}_{2}$ (cylinder) supply. The precise $F \mathrm{I}, \mathrm{O}_{2}$ being delivered was monitored using a fuel-cell analyser (5590 Oxygen Monitor; Hudson, CA, USA) placed in the inspiratory limb of the circuit.

NO was administered using a simple constant flow system delivering $1 \%$ NO in $\mathrm{N}_{2}$ (BOC Special Gases, Guildford, UK) into the inspiratory limb of the ventilator circuit (Evita II; Draeger, Lubeck, Germany), via a low-flow meter (Ohmeda, Hatfield, UK). The concentration of $\mathrm{NO}$ and nitrogen dioxide $\left(\mathrm{NO}_{2}\right)$ in the circuit was measured using a fuel-cell analyser (Micro Medicals, Rochester, UK) with a long response time ( $\sim 10 \mathrm{~s})$. $\mathrm{NO}$ and $\mathrm{NO}_{2}$ were scavenged from the expiratory limb of the circuit using an ABEK HgCONO-P3 filter (Drager Industrial Ltd, Hemel Hempstead, UK).

\section{Experimental protocol}

After the commencement of IPPV using an $F \mathrm{I}, \mathrm{O}_{2}$ of 0.21 , each subject was left for $15 \mathrm{~min}$ to achieve a steady state, following which a multisection scan was obtained at a level $2-3 \mathrm{~cm}$ above the right hemi-diaphragm. The $F \mathrm{I}, \mathrm{O}_{2}$ was then decreased to 0.12 , and a second multisequence scan obtained at the same level, after a further period of $15 \mathrm{~min}$. NO was then administered by inhalation at a dose of 10 parts per million (ppm), the $F \mathrm{I}, \mathrm{O}_{2}$ remaining constant at 0.12 , and a final multisequence scan performed at the same level, after a further period of $15 \mathrm{~min}$. During the study, subjects were monitored for arterial $\mathrm{O}_{2}$ saturation, end-tidal carbon dioxide $\left(\mathrm{CO}_{2}\right)$ concentration and ECG, but neither invasive haemodynamic nor blood gas data were recorded. During each inspiratory breath-hold manoeuvre, the plateau pressure (Pplat), and VT were noted from the ventilator liquid crystal display.

\section{Calculation of perfusion using electron-beam computed tomography}

Using EBCT and following the Sapirstein principle, perfusion can be calculated using equations derived from conventional microsphere approaches to blood flow analysis $[15,16]$.

$$
\mathrm{PBF} / \mathrm{V}=\frac{\Delta \mathrm{Pul}}{\int \mathrm{C}_{\mathrm{DA}} \mathrm{dt}}
$$

where $\mathrm{PBF} / \mathrm{V}$ is blood flow per unit volume of lung, $\Delta \mathrm{Pul}$ is the peak Hounsfield Unit (HU) change due to contrast material and $\int \mathrm{C}_{\mathrm{DA}} \mathrm{dt}$ is the area under the time density curve for the descending aorta by a gamma variate fit.

To express blood flow per unit volume of lung parenchyma, it is assumed that the region of interest (ROI) is composed of air and water (i.e. blood and parenchyma). The disparate densities of these components allow the fraction of each to be calculated using the CT gray scale or HU for any ROI. For example, the water fraction can be calculated by subtracting the CT value of pure air from the mean CT value of an ROI to provide a value reflecting the amount (density) of parenchyma and blood present in the selected region. Comparing this value to the continuum ranging from water $(0 \mathrm{HU})$ to air $(1000 \mathrm{HU})$, allows the percentage of the ROI which is water (blood and parenchyma) to be calculated as follows [17]:

$$
\text { (blood and parenchyma })=\frac{\text { CT ROI }- \text { CT air }}{\text { CT blood }- \text { CT air }}
$$

The air fraction of an ROI, is simply 1-water fraction. Further, the amount of blood present within an ROI can be computed by comparing the time/density curve of the ROI to that of the feeding/draining vessel:

$$
\text { Blood }=\frac{\int \mathrm{C}_{(\mathrm{ROI})} \mathrm{dt}}{\int \mathrm{C}_{(\mathrm{DA})} \mathrm{dt}}
$$

where $\mathrm{C}_{(\mathrm{ROI})} \mathrm{dt}$ and $\mathrm{C}_{(\mathrm{DA})} \mathrm{dt}$ represent the area under the time/ density curve of the ROI and descending aorta, respectively. Subtracting the result from the water fraction produces the percentage of the ROI that is lung parenchyma. Blood flow per unit volume of lung parenchyma can then be calculated by dividing the absolute blood flow per $\mathrm{mL}$ of lung tissue (blood, parenchyma and air) by the fraction of parenchyma in the ROI.

Measurement of cardiac output using EBCT is based on the Stewart-Hamilton equation, with iodinated contrast medium in the aorta used as an indicator $[16,18]$ :

$$
\text { Flow }\left(\mathrm{L}^{-1}\right)=\frac{\mathrm{K} \times 300 \times V \times 60}{\mathrm{AUC} \times 1,000}
$$

where $\mathrm{K}$ is the constant relating $\mathrm{HU}$ value to I concentration (HU mg I), 300 is the amount of I per mL of contrast 
$\left(\mathrm{mg} \mathrm{I} \cdot \mathrm{mL}^{-1}\right), V$ is volume of contrast injected $(\mathrm{mL}), 60$ is correction factor from seconds to minutes, AUC is area under descending aorta time/density curve and 1,000 is the correction from $\mathrm{mL}$ to $\mathrm{L}$.

\section{Image analysis}

ROI were placed in five regions, at 10, 30, 50, 70 and $90 \%$ of the dependent-nondependent lung distance, and time/ density curves were constructed for each ROI using a gammavariate fit to exclude recirculation. Two approaches were used to calculate perfusion in each sample region; first, a single ROI $\left(\mathrm{ROI}_{\mathrm{S}}\right.$ ) with a sample area of $\sim 7-10 \mathrm{~cm}^{2}$ (volume 4-6 $\left.\mathrm{cm}^{3}\right)$ and secondly, smaller multiple ROI $\left(\mathrm{ROI}_{\mathrm{M}}\right)$ with a sample area $\sim 1 \mathrm{~cm}^{2}$ (volume $0.6 \mathrm{~cm}^{3}$ ), were used (fig. 1). In both cases, ROI were placed to avoid large blood vessels. Perfusion was calculated using the technique previously outlined. Relative perfusion, expressed as a fraction of the mean perfusion of the given section, derived using a freehand device to define a ROI that included the whole of the lung section except for the hilar and large central vessels, was also calculated.
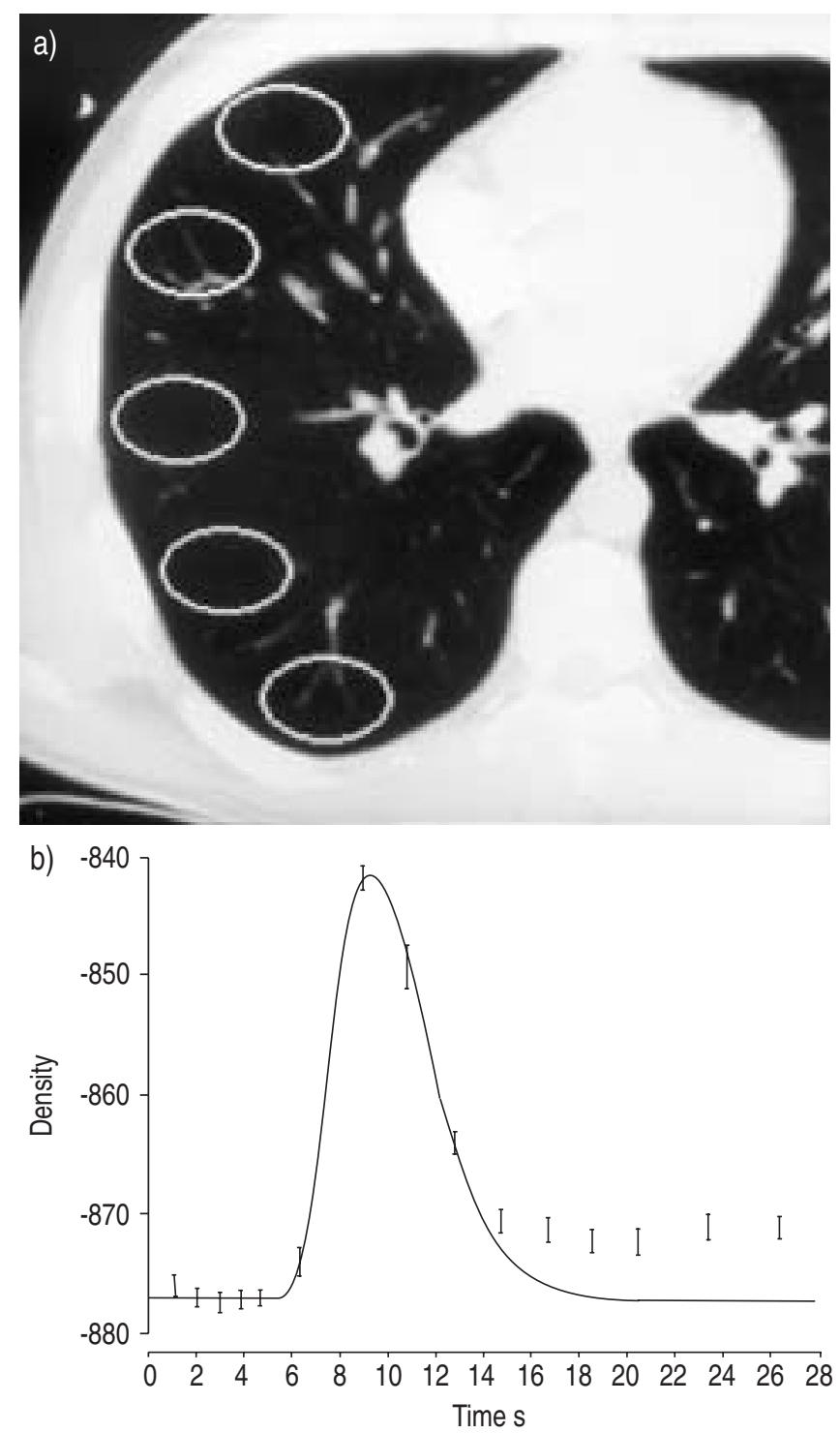

\section{Statistical analysis}

Comparisons between ventilatory and haemodynamic parameters during each intervention and differences in regional perfusion $\mathrm{ROI}_{\mathrm{S}}$ under the same study conditions were compared using analyses of variance (ANOVA). For comparisons of perfusion distributions $\left(\mathrm{ROI}_{\mathrm{S}}\right)$ under different study conditions, a two-way ANOVA was applied. For comparison of individual perfusion gradients between interventions $\left(\mathrm{ROI}_{\mathrm{M}}\right)$ linear regression analysis was applied, using the Standard Two Stage method [19]. For relative perfusion compared with the section mean under normoxic conditions, standard linear regression analysis was applied to group data, and the square of the coefficient of correlation was used to quantify what proportion of flow variability was explained by the independent variable.

\section{Results}

All five subjects tolerated the experimental protocol without difficulty or adverse reactions. The results of haemodynamic
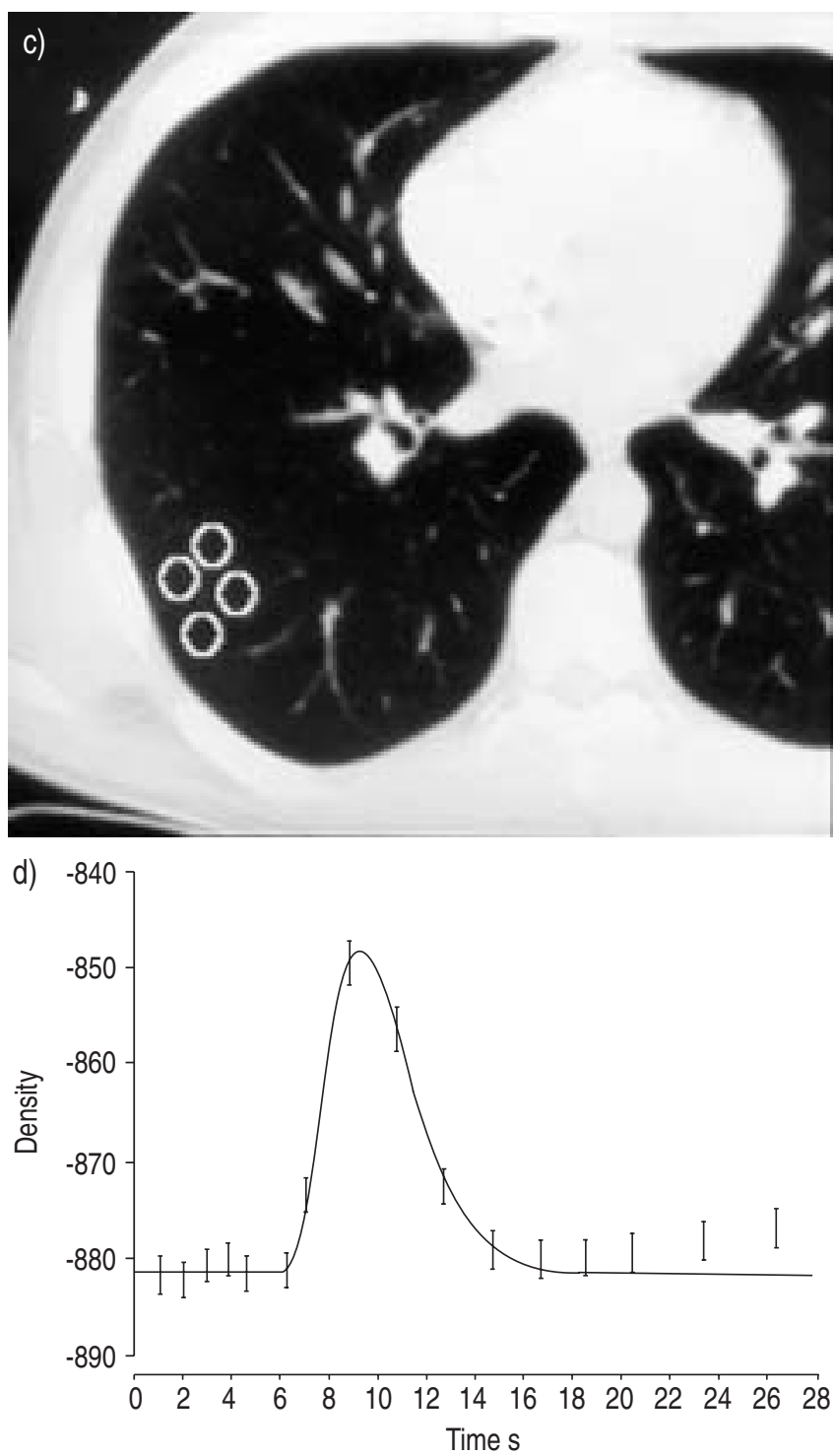

Fig. 1.-Image analysis. Within the lung sections examined, regions of interest (ROI; indicated by white circles) were placed at a) $10,30,50,70,90 \%$ (from lower to upper) of the vertical lung height. c) Multiple ROI examining perfusion at $\sim 30 \%$ of the vertical lung height. b, d) Using the scanner's proprietary software, time/density curves were constructed for each ROI, with a gamma-variate fit employed to exclude re-circulation of contrast. 
Table 1.- Haemodynamic and ventilatory data

\begin{tabular}{|c|c|c|c|c|}
\hline \multirow[t]{2}{*}{ Variable } & \multicolumn{3}{|c|}{$F \mathrm{I}, \mathrm{O}_{2}$} & \multirow[t]{2}{*}{ p-value } \\
\hline & 0.21 & 0.12 & $0.12+\mathrm{NO}$ & \\
\hline$V \mathrm{~T} \mathrm{~L}$ & $0.64 \pm 0.03$ & $0.63 \pm 0.03$ & $0.64 \pm 0.03$ & $\mathrm{~ns}^{\mathrm{a}} / \mathrm{ns}^{\mathrm{b}}$ \\
\hline Pplat $\mathrm{cmH}_{2} \mathrm{O}$ & $5.5 \pm 1.0$ & $5.0 \pm 0.4$ & $5.5 \pm 0.8$ & $\mathrm{~ns}^{\mathrm{a}} / \mathrm{ns}^{\mathrm{b}}$ \\
\hline $\mathrm{Sa}, \mathrm{O}_{2} \%$ & $98.7 \pm 0.5$ & $83.4 \pm 0.8$ & $83.5 \pm 1.4$ & $* * \mathrm{a} / \mathrm{ns}^{\mathrm{b}}$ \\
\hline $\mathrm{ETCO}_{2} \mathrm{mmHg}$ & $37.8 \pm 0.6$ & $35.7 \pm 0.8$ & $34.5 \pm 0.7$ & $\mathrm{~ns}^{\mathrm{a}} / \mathrm{ns}^{\mathrm{b}}$ \\
\hline Heart rate min & $67.8 \pm 4.1$ & $84.7 \pm 6.2$ & $80.2 \pm 5.9$ & $* * a / n^{b}$ \\
\hline$\Delta \mathrm{CO} \%$ & 0 & $27.2 \pm 4.8$ & $20.8 \pm 3.4$ & $* * \mathrm{a} / * \mathrm{~b}$ \\
\hline
\end{tabular}

Data are presented as mean \pm SEM; $F \mathrm{I}_{1} \mathrm{O}_{2}$ : fractional concentration of oxygen in inspired gas; $V \mathrm{~T}$ : tidal volume; Pplat: plateau pressure; $\mathrm{S}_{\mathrm{a}, \mathrm{O}_{2}}$ : arterial oxygen saturation; $\mathrm{ETCO}_{2}$ : end-tidal carbon dioxide; $\mathrm{CO}$ : carbon monoxide. ${ }^{\mathrm{a}}$ : comparing 0.21 versus 0.12 ; $^{\mathrm{b}}$ : comparing 0.12 versus $0.12+\mathrm{iNO}$. *: $\mathrm{p}<0.05$; **: $\mathrm{p}<0.01$.

and ventilatory variables during the scanning protocol are detailed in table 1. VT and Pplat remained unchanged throughout the scanning protocol. With the introduction of the hypoxic gas mixture, arterial oxygen saturation $\left(\mathrm{Sa}, \mathrm{O}_{2}\right)$ fell significantly, accompanied by a slight, but not significant, reduction in end-tidal $\mathrm{CO}_{2}$. Heart rate increased significantly with the induction of hypoxia, with no further change following the introduction of iNO (14.8 ppm).

Using $\mathrm{ROS}_{\mathrm{S}}$, under normoxic conditions a nondependent to dependent gradient in regional perfusion was observed, which was maximal at $\sim 50 \%$ of the nondependent/dependent distance. Perfusion remained relatively constant in the most dependent regions of the lung (fig. 2). In contrast, under hypoxic conditions there was evidence that whilst perfusion in dependent regions remained relatively constant, there was increased perfusion in nondependent regions, with more uniform distribution across the lung section, although this failed to reach statistical significance (fig. 2). The addition of iNO under hypoxic conditions led to increased perfusion $(\mathrm{p}=0.014)$, most noticeable in dependent regions. A return to a nondependent to dependent pattern of increasing perfusion was apparent (fig. 2).

When examining regional perfusion using $\mathrm{ROI}_{\mathrm{M}}$, a nondependent/dependent gradient was again detected under both normoxic and hypoxic conditions (fig. 3a). A decrease in

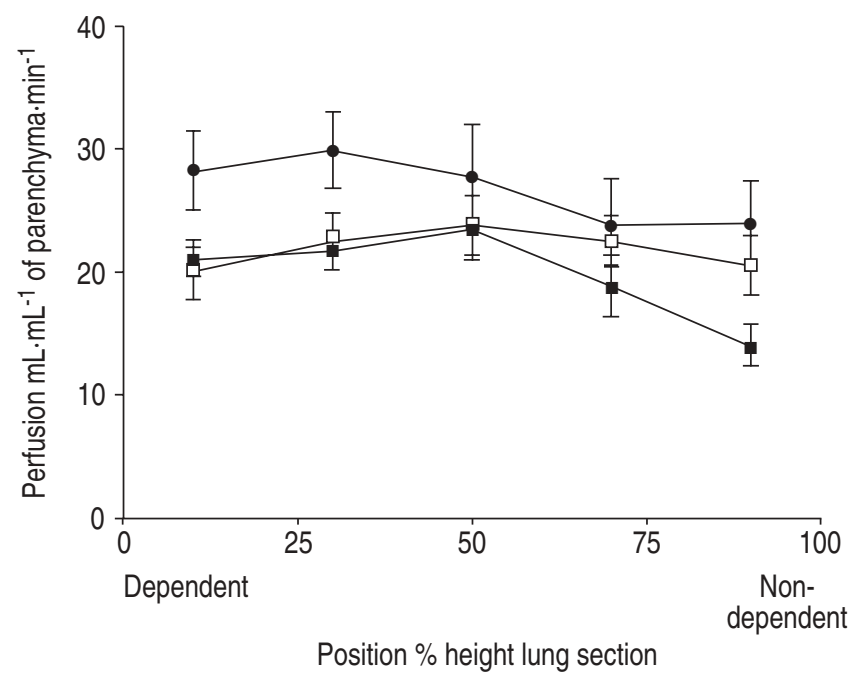

Fig. 2. - Distribution of pulmonary perfusion single regions of interest (mean \pm SEM) ( $\mathbf{\square}$ : fractional concentration of oxygen in inspired gas $\left(F \mathrm{I}, \mathrm{O}_{2}\right) 0.21 ; \square: F \mathrm{I}_{1} \mathrm{O}_{2} 0.12$. $\left.: F \mathrm{I}, \mathrm{O}_{2} 0.12+\mathrm{iNO}\right)$.
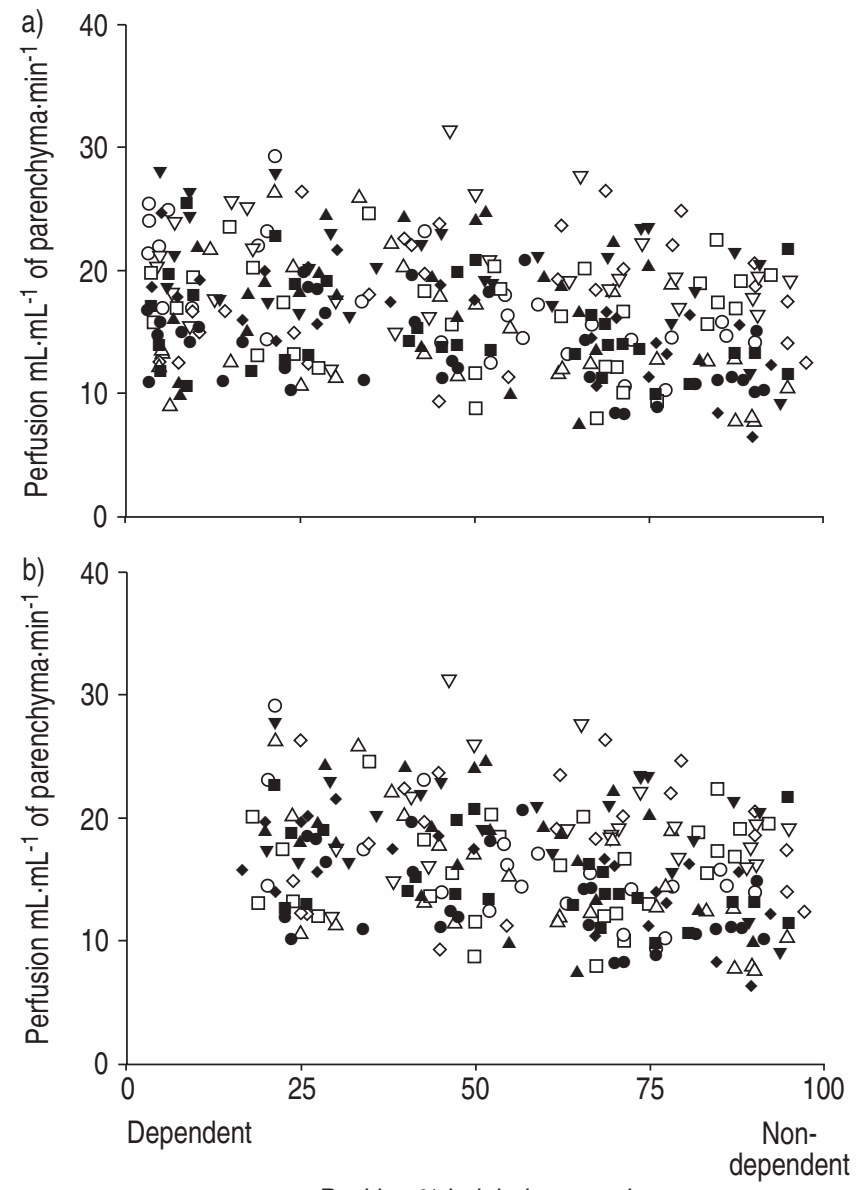

Position \% height lung section

Fig. 3. - Distribution of pulmonary perfusion multiple regions of interest (closed symbols: fractional concentration of oxygen in inspired gas $\left(F, \mathrm{O}_{2}\right)$ 0.21. open symbols: $F_{\mathrm{I}} \mathrm{O}_{2} 2.12$; individual shapes represent each subject). a) All observations. b) Data from lowest $20 \%$ of lung section excluded.

perfusion to the lowest regions of the lung section, particularly under normoxic conditions, was also apparent. In such areas, other factors, such as differences in alveolar ventilation and increased tissue pressure, may exert an additional effect on pulmonary perfusion. After excluding such regions (lower $20 \%$ of section), observation of group data suggested that the perfusion gradient was more uniform under hypoxic than normoxic conditions (fig. 3b). However, analysis of individual perfusion gradients under both conditions, did not support this observation $(p=0.37)$. To correct the data for variations in perfusion consequent upon inter-subject differences in cardiac output perfusion, values were compared with the mean perfusion of the respective lung section. Under normoxic and hypoxic conditions, a nondependent to dependent gradient of increasing perfusion was again demonstrated. Examining group data again suggested a more uniform distribution of perfusion under hypoxic conditions (fig. 4a). These observations were more evident if perfusion values from the lowermost $(20 \%)$ of the lung section were excluded (fig. $4 \mathrm{~b})$, with the individual perfusion gradients becoming more uniform under hypoxic conditions $(\mathrm{p}=0.08)$. Moreover, the use of a high spatial resolution technique confirmed marked perfusion heterogeneity in anatomically close regions of lung (fig. 4a, b). Standard linear regression analysis was applied to group data under baseline (normoxia) conditions, and the square of the linear correlation estimated $\left(r^{2}=0.28\right)$.

Both analyses revealed that the addition of iNO under 
hypoxic conditions resulted in an increase in perfusion values throughout the lung section $\left(\mathrm{p}<0.01 \mathrm{ROI}_{\mathrm{S}}\right)$ (fig. 2$),(\mathrm{p}<0.01$ $\mathrm{ROI}_{\mathrm{M}}$ ) (fig. 5).
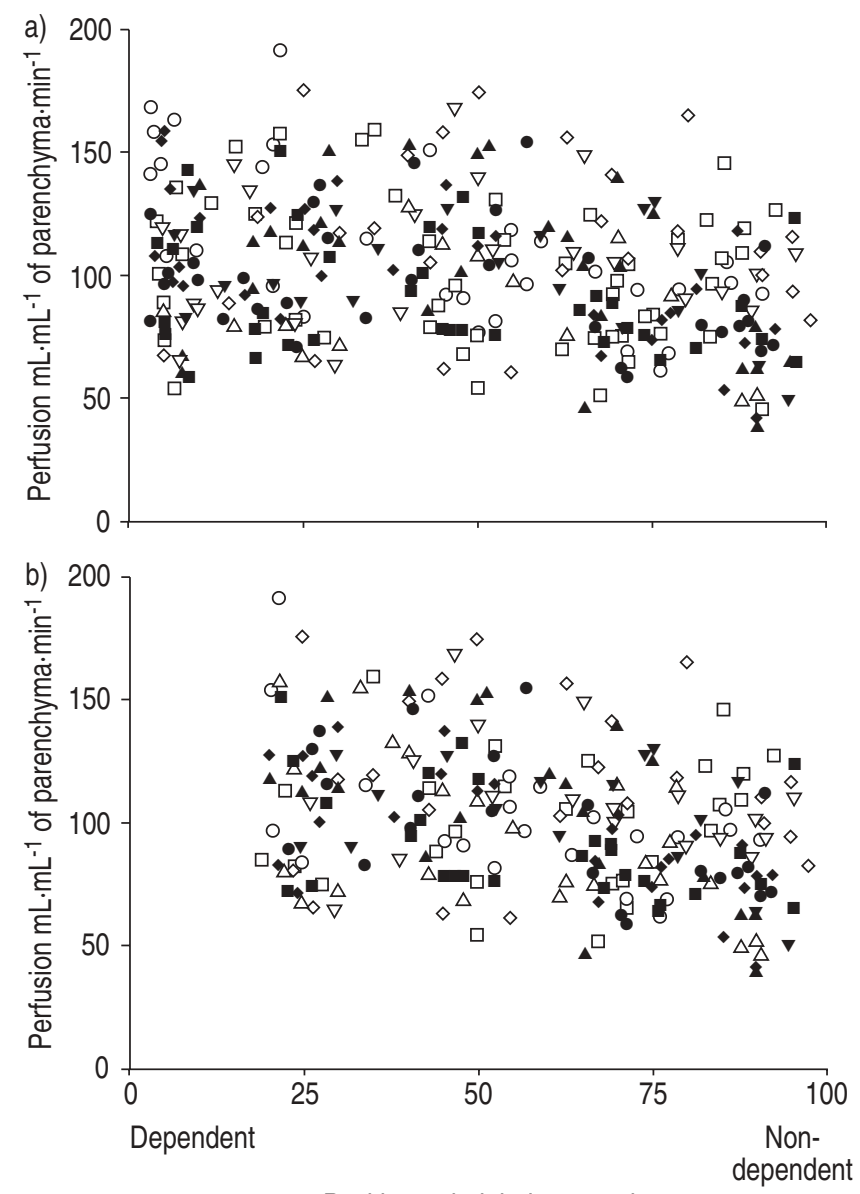

Position \% height lung section

Fig. 4.-Distribution of relative pulmonary perfusion multiple regions of interest (closed symbols: fractional concentration of oxygen in inspired gas $\left(F_{1}, \mathrm{O}_{2}\right) 0.21$. open symbols: $F_{1}, \mathrm{O}_{2} \quad 0.12$; individual shapes represent each subject). a) All observations. b) Data from lowest $20 \%$ of lung section excluded.

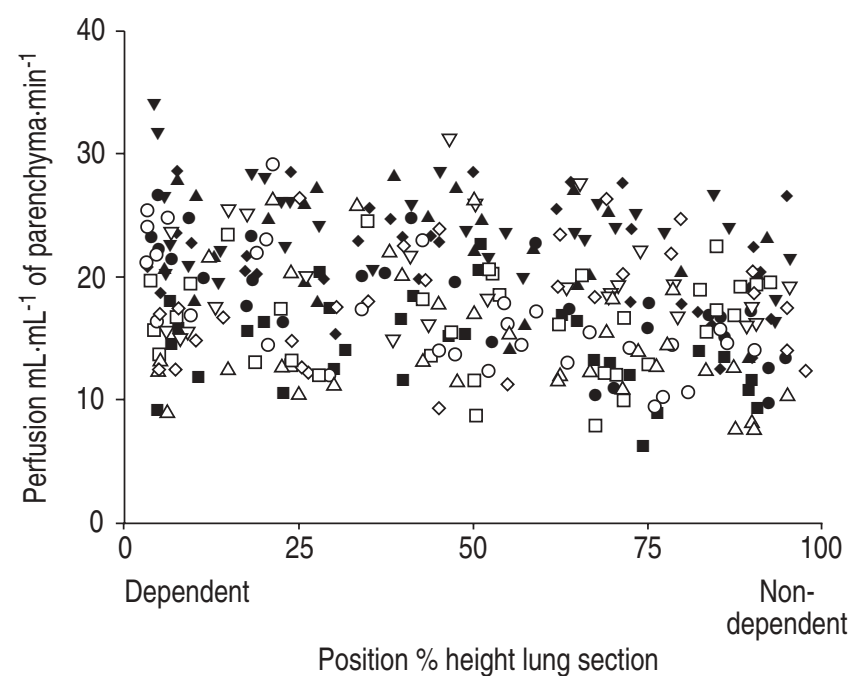

Fig. 5. - Distribution of pulmonary perfusion multiple regions of interest (closed symbols: fractional concentration of oxygen in inspired gas $\left(\mathrm{F}, \mathrm{O}_{2}\right)$ 0.21 . open symbols: $F_{1}, \mathrm{O}_{2} 0.12$; individual shapes represent each subject).

\section{Discussion}

This study demonstrated a number of important findings. First, that the relative-regional pulmonary perfusion may be quantified in normal human subjects using EBCT, obtaining values of perfusion comparable to those obtained with existing, less clinically applicable, techniques. Secondly, it has been confirmed that a vertical gradient of perfusion exists under resting conditions in the supine human lung. Thirdly, under hypoxic conditions evidence of increased perfusion in nondependent lung regions resulting in a more uniform distribution of pulmonary perfusion was demonstrated. Finally, the addition of iNO during hypoxia led to an increase in perfusion across all regions of the basal lung section, consistent with the reversal of HPV, with redistribution of pulmonary blood flow to the lung bases. Under all conditions, high spatialresolution analysis confirmed a marked degree of perfusion heterogeneity between anatomically related regions of the lung section.

Despite these positive findings, this study had a number of limitations in terms of experimental method. First, numerous interacting phenomenon are likely to be responsible for regulating regional pulmonary blood flow. Although the use of IPPV enabled accuracy in terms of the administration of gas mixtures and airway pressures to be maintained, the authors were unable to control for the effects of other variables. Thus, hypoxia-induced changes in cardiac output (as was shown here, table 1), and decreased alveolar $\mathrm{CO}_{2}$ (reflected here in changes in end-tidal $\mathrm{CO}_{2}$, table 1) may also have influenced the redistribution of blood flow during hypoxaemia rather than the induction of HPV per se. Secondly, variability inherent in the assumptions of the indicator dilution technique may lead to inaccuracies. Thus, the indicator must mix completely with blood, should be as near as possible a bolus and must not itself influence flow. Others have shown that radiographic contrast material may influence regional pulmonary blood flow [20, 21], although comparison of the results from repeated measurements in the current study made before and after each intervention (hypoxia, hypoxia plus NO) would effectively control for such variability.

The primary aim of this investigation was to establish the nature and extent of changes in regional blood flow in response to hypoxia, without and with the addition of iNO. Previous investigators have used relative estimates of perfusion, either comparing that of one region to that of another or quantifying $V^{\prime} / Q^{\prime}$ relationships. Absolute measures of pulmonary perfusion are difficult to obtain using currently available techniques. In experimental animals, such values can be obtained using microspheres, and positron emission tomography has been used in humans, and have shown comparable values to those corrected perfusion data reported here [22, 23]. Further, data from the current study are in accordance with estimates of pulmonary perfusion acquired using EBCT in experimental animals $[16,24]$. EBCT measures of perfusion, both in this and in previous animal studies, have tended to be slightly lower in comparison to values obtained using other techniques, possibly due to the limitations of the technique outlined above and the fact that measurement of tissue perfusion with EBCT is based on microsphere algorithms. Consequently, any loss of indicator from the tissue results in an underestimation of the absolute value of perfusion $[15,25,26]$.

The influence of gravity on the distribution of pulmonary perfusion identified here has been explained traditionally through the interaction of alveolar, pulmonary arterial and venous and interstitial pressures [8, 9]. Recent studies using high spatial-resolution microsphere techniques have suggested that the branching pattern of the pulmonary vascular 
tree leads to more heterogeneity of perfusion than could be explained by gravity alone; the so-called fractal hypothesis $[10,11]$. Using these techniques, gravity was found to account for only $2-10 \%$ of the perfusion heterogeneity in the prone and supine postures in dogs [11], and for $\leqslant 27 \%$ in upright baboons [10]. In a recent study using EBCT, the authors reported similar perfusion heterogeneity in healthy human subjects, analysis revealing that gravity accounts for between $22-31 \%$ and $27-41 \%$ of this perfusion heterogeneity in the supine and prone positions, respectively [12]. In the current study, the application of a higher spatial-resolution technique again revealed marked perfusion heterogeneity between anatomically close regions of lung. Under baseline conditions, the effect of gravity accounted for, at most, $28 \%$ of this perfusion heterogeneity. Application of small levels of positive pressure would likely increase any nondependent to dependent gradient in perfusion [27-30].

Pulmonary vasoconstriction in response to alveolar hypoxia has been shown to occur in all mammalian species including humans [1]. Although the magnitude of the response may vary from one individual to another [1, 14], ventilation with $F \mathrm{I}, \mathrm{O}_{2} 0.12$ in the current study resulted in a changes in $\mathrm{Sa}, \mathrm{O}_{2}$, heart rate and (estimated) cardiac output compatible with previous studies using direct measurements of $P$ pa $[1,7,31]$. Studies using other techniques, performed in both experimental animals and humans, have suggested that under conditions of generalised hypoxia there is a redistribution of blood from dependent to nondependent lung regions [32-34]. Studies in experimental animals have shown that this redistribution of blood flow is secondary to recruitment of previously unperfused capillaries in these regions, with minimal evidence of capillary dilatation [35]. This recruitment phenomenon has been found to correlate strongly with the increased pulmonary artery pressure [36], secondary to arterial vasoconstriction seen under conditions of generalised hypoxia, with other possible variables (changes in left atrial pressure and cardiac output) having a minimal role. It is not immediately obvious how recruitment of a local capillary bed can occur when hypoxia causes pulmonary artery vasoconstriction. However, increased pulmonary artery pressure caused by generalised vasoconstriction tends to reduce the normally existing gravitational gradient of pulmonary perfusion by increasing flow in Zone II conditions and decreasing the amount of lung under Zone I conditions. This recruitment of the capillary bed in nondependent regions is believed to increase the area available for gaseous exchange under conditions of generalised hypoxia [37].

In the current investigation, during hypoxaemic conditions there was also evidence of increased perfusion in nondependent lung regions, leading to a more uniform vertical gradient of perfusion. Although this change was small, there are several reasons why changes in regional perfusion may have been under estimated. First, subjects were mechanically ventilated, and the scans were performed during an inspiratory breath-hold manoeuvre. Although the plateau pressures generated during each scan study were low $(5.5 \pm 0.7,5.33 \pm 0.8$, $\left.5.5 \pm 0.6 \mathrm{cmH}_{2} \mathrm{O}\right)$, lung inflation above functional residual capacity [8], and the application of positive pressure ventilation [26-29], both resulted in a redistribution of blood from nondependent towards dependent regions. Secondly, the configuration of the EBCT scanner results in the dose of radiation to the patient and its scatter and noise distribution being radially asymmetrical, with increased noise to signal ratios in the upper quadrant, which could impair the accuracy of this technique in measuring perfusion in regions within this area, which corresponds to the nondependent regions of the lung slice. Thirdly, radiographic contrast agents, even nonionic media, are known to be mild vasodilators. Certain vasodilator compounds are known to modulate the effects of HPV [14], and in particular, reverse the redistribution observed with hypoxia, there being derecruitment of capillaries in nondependent regions, with blood flow redistributed back towards dependent regions [37]. Finally, in experimental models and animal experiments, EBCT measures of perfusion have been shown to increasingly underestimate true perfusion at higher flow rates due to increased washout of contrast. It is possible that with the increase in cardiac output seen under hypoxic conditions in the current study, perfusion estimates underestimated the true increase in perfusion seen in nondependent lung regions. However, previous studies have shown that the increased perfusion seen in these regions is due to capillary recruitment, which correlates poorly with changes in cardiac output or flow [36]. The deciding factor in the current experiment would depend on the degree in which the increased perfusion in nondependent regions was dependent on capillary recruitment, which should have no effect or possibly improve perfusion estimates due to reductions in capillary flow rates, versus increased flow through previously perfused capillaries. Such data is not available with this technique.

Inhaled nitric oxide has been shown to reverse hypoxic pulmonary vasoconstriction in lambs [5], adult sheep [6], and normal human subjects [7]. In the current investigation, following the addition of inhaled nitric oxide under hypoxic conditions, perfusion values increased in all regions of the lung section, consistent with the reversal of hypoxic pulmonary vasoconstriction. However, this was in the setting of an overall decrease in cardiac output. How can this finding be explained? First, was the measure of cardiac output accurate? Cardiac output measurements using electron-beam computed tomography are based on indicator dilution techniques, and have been demonstrated to be less accurate at increasing flow rates $[9,25]$, with a tendency to over estimate true flow. Such an inaccuracy fails to explain the observed data. Alternatively, conservation of blood flow predicts that if cardiac output were to decrease, then average pulmonary blood flow would also have to decrease. Therefore, the finding that blood flow increased in the basal or caudal lung section in this study may suggest redistribution from another region of the lung. In the supine position other investigators have reported horizontal "isogravity" gravity gradients, with caudal blood flow being less than cranial [38, 39]. Under conditions of hypoxia, these gradients are exaggerated [32], with cranial flow increasing relative to caudal flow, suggesting that the caudal vessels are more responsive in terms of hypoxic pulmonary vasoconstriction [40], and possibly therefore, to reversal of this phenomenon. In the current study, only one lung section in the caudal region of the lung was investigated, and therefore this hypothesis cannot be fully confirmed.

\section{References}

1. Fishman AP. Hypoxia on the pulmonary circulation. How and where it acts. Circ Res 1976; 38: 221-231.

2. Von Euler US, Liljestrand G. Observations on the pulmonary arterial pressure in the cat. Acta Physiol Scand 1946; 12: 301-306.

3. Dantzker DR, Brook CJ, Dehart P, Lynch JP, Weg JG. Ventilation perfusion distributions in the adult respiratory distress syndrome. Am Rev Respir Dis 1979; 20: 1039-1052.

4. Moncada S, Palmer RMJ, Higgs EA. Nitric oxide; physiology, pathophysiology and pharmacology. Pharmacol Rev 1991; 43: 109-142.

5. Frostell CG, Fratacci M, Wain JC, Zapol WM. Inhaled nitric oxide: A selective pulmonary vasodilator reversing hypoxic pulmonary vasoconstriction. Circulation 1991; 83: 2038-2047. 
6. Pison U, Lopez FA, Heidelmeyer CF, Rossaint R, Falke KJ. Inhaled nitric oxide reverses hypoxic pulmonary vasoconstriction without impairing gas exchange. Anesthesiology 1993; 74: 1287-1292.

7. Frostell CG, Blomqvist H, Lundberg J, Zapol WM. Inhaled nitric oxide reverses human hypoxic pulmonary vasoconstriction without causing systemic vasodilation. Anesthesiology 1993; 78: 427-435.

8. Hughes JMB, Glazier JE, Maloney JE, West JB. Effect of lung volume on the distribution of pulmonary blood flow in man. Respir Med 1968; 4: 58-72.

9. West JB, Dollery CT, Naimark A. Distribution of blood flow in isolated lung; relation to vascular and alveolar pressures. J Appl Physiol 1964; 19: 713-724.

10. Glenny RW, Bernard S, Robertson HT, Hlastala MP. Gravity is an important but secondary determinant of regional pulmonary perfusion in upright primates. $J$ Appl Physiol 1999; 86: 623-632.

11. Glenny RW, Lamm WJE, Albert RK, Robertson HT. Gravity is a minor determinant of pulmonary blood flow distribution. J Appl Physiol 1991; 71: 620-629.

12. Jones AT, Hansell DM, Evans TW. Pulmonary perfusion in supine and prone positions: an electron-beam computed tomography study. J Appl Physiol 2001; 90: 1342-1348.

13. Fishman AP, Fritts HW, Cournand A. Effects of acute hypoxia and exercise on the pulmonary circulation. Circulation 1960; 22: 204-215.

14. Naeije RL, Melot C, Mols P, Hallemans R. Effects of vasodilators on hypoxic vasoconstriction in normal man. Chest 1982; 82: 404410.

15. Wolfkiel CJ, Fergusson JL, Chomka EV, et al. Measurement of myocardial blood flow by ultrafast computed tomography. Circulation 1987; 76: 1262-1273.

16. Wolfkiel CJ, Rich SA. Analysis of regional pulmonary enhancement in dogs using ultrafast computed tomography. Invest Radiol 1992; 27: 211-216.

17. Tajik JK, Kugelmass SD, Hoffman EA. An automated method for relating regional pulmonary structure and function: integration of dynamic multislice CT and thin slice high-resolution CT. SPIE Proceed 1993; 1905: 339-350.

18. Wolfkiel CJ, Fergusson JL, Chomka EV, Law WR, Brundage BH. Determination of cardiac output by ultrafast computed tomography. Am J Physiol Imaging 1986; 1: 117123.

19. Feldman HA. Families of lines: random effects in linear regression analysis. J Appl Physiol 1988; 64: 1721-1732.

20. Peck WW, Slutsky RA, Hackney DB, Mancini GBJ, Higgins CB. Effects of contrast on pulmonary hemodynamics: comparison of ionic and non-ionic agents. Radiology 1983; 149: 371-374.

21. Slutsky RA, Hackney DB, Peck WW, Higgins CB. Extravascular lung water: effects of ionic and non-ionic contrast media. Radiology 1983; 149: 375-378.

22. Brudin LH, Rhodes SO, Valind SO, Jones T, Hughes JMB. Interrelationships between regional blood flow, blood volume, and ventilation in supine humans. J Appl Physiol 1998; 76: 1205-1210.
23. Reed JH, Wood EH. Effect of body position on vertical distribution of pulmonary blood flow. J Appl Physiol 1970; 28: $303-311$.

24. Larsen RL, Bridges CR, Beck KC, Hoffman EA. Regional pulmonary blood flow via cine $\mathrm{x}$-ray computed tomography (abstract). FASEB J 1990; 4: 1074.

25. Ludman PF, Darby M, Tomlinson N, Poole-Wilson PA, Rees S. Cardiac flow measurement by ultrafast CT: Validation of continuous and pulsatile flow. J Comput Assist Tomogr 1992; 16: 795-803.

26. Rumberger JA, Feiring AJ, Lipton MJ, Higgins CB, Ell SR, Marcus M. Use of ultrafast computed tomography to quantitate regional myocardial perfusion: A preliminary report. J Am Coll Cardiol 1987; 9: 59-69.

27. Hedenstierna G, White FC, Mazzone R, Wagner PD. Redistribution of pulmonary blood flow in the dog with PEEP ventilation. J Appl Physiol 1979; 46: 278-287.

28. Hedenstierna G, White FC, Wagner PD. Spatial distribution of pulmonary blood flow in the dog with PEEP ventilation. J Appl Physiol 1979; 47: 938-946.

29. Kallas HJ, Domino KB, Glenny RW, Anderson EA, Hlastala MP. Pulmonary blood flow redistribution with low levels of positive end-expiratory pressure. Anesthesiology 1998; 88: 1291-1299.

30. Theissen JL, Fischer SR, Traber LD, Traber DL. Pulmonary blood flow regulation: influence of positive pressure ventilation. Respir Physiol 1995; 102: 251-260.

31. Rossaint R, Falke KJ, Lopez FA, Slama K, Pison U, Zapol WM. Inhaled nitric oxide in adult respiratory distress syndrome. N Engl J Med 1993; 328: 399-405.

32. Dawson A. Regional pulmonary blood flow in sitting and supine man during and after acute hypoxia. $J$ Clin Invest 1969; 8: 301-310.

33. Dugard A, Naimark A. Effect of hypoxia on the distribution of pulmonary blood flow. J Appl Physiol 1967; 23: 663-671.

34. Neumann PH, Kivlen CM, Johnson A, Minnear FL, Malik AB Effect of alveolar hypoxia on regional pulmonary perfusion. J Appl Physiol 1984; 56: 338-342.

35. Wagner WW, Latham LP. Pulmonary capillary recruitment during airway hypoxia in the dog. J Appl Physiol 1975; 39: 900-905.

36. Wagner WW, Latham LP, Capen RL. Capillary recruitment during airway hypoxia: role of pulmonary artery pressure. J Appl Physiol 1979; 47: 383-387.

37. Capen RL, Wagner WW. Intrapulmonary blood flow redistribution during hypoxia increases gas exchange surface area. J Appl Physiol 1982; 52: 1575-1581.

38. Engel LA, Prefaut C. Cranio-caudal distribution of inspired gas and pulmonary perfusion in supine man. Respir Physiol 1981; 45: 43-53.

39. Orphanidou D, Hughes JMB, Meyers MJ, Al-Suhali AR, Henderson B. Tomography of regional ventilation and perfusion using kryptonite $81 \mathrm{~m}$ in normal subjects and asthmatic patients. Thorax 1986; 41: 542-551.

40. Fowler KT, Reed J. Effect of alveolar hypoxia on zonal distribution of pulmonary blood flow. J Appl Physiol 1963; 18: $244-250$ 